Article

\title{
Environmental Literacy on Ecotourism: A Study on Student Knowledge, Attitude, and Behavioral Intentions in China and Taiwan
}

\author{
Wei-Ta Fang ${ }^{1, *}(\mathbb{D})$, Ching-Yu Lien ${ }^{2}$, Yueh-Wen Huang ${ }^{3}$, Guosheng Han ${ }^{4}$, Guey-Shin Shyu ${ }^{5, *}$, \\ Jui-Yu Chou ${ }^{6}$ and Eric $\mathrm{Ng}^{7, *}$ \\ 1 Graduate Institute of Environmental Education, National Taiwan Normal University, Taipei 11677, Taiwan \\ 2 Department of Tourism Management, School of Geography and Tourism, Jiaying University, \\ Meizhou 514015, China; cylien@jyu.edu.cn \\ 3 Department of Tourism, Shih Hsin University, Taipei 11604, Taiwan; hwhuang@mail.shu.edu.tw \\ 4 Department of Tourism Management, School of Business Administration, Shandong University at Weihai, \\ Weihai 264209, China; hanguosheng@sdu.edu.cn \\ 5 Department of Tourism, Tungnan University, Shenkeng, New Taipei City 22202, Taiwan \\ 6 Department of Biology, National Changhua University of Education, Changhua 50007, Taiwan; \\ jackyjau@cc.ncue.edu.tw \\ 7 School of Management and Enterprise, University of Southern Queensland, Toowoomba, \\ QLD 4350, Australia \\ * Correspondence: wtfang@ntnu.edu.tw (W.-T.F.); gsshyu@mail.tnu.edu.tw (G.-S.S); eric.ng@usq.edu.au \\ (E.N.); Tel.: +886-9-3985-9399 (W.-T.F.); +886-2-8662-5958 (ext. 723) (G.-S.S); +61-7-4631-1298 (E.N.)
}

Received: 24 April 2018; Accepted: 2 June 2018; Published: 5 June 2018

\begin{abstract}
This study aims to gain further insights to Chinese and Taiwanese university students' environmental literacy on ecotourism. A structural equation model is developed and validated in an effort to explore the differences between Chinese and Taiwanese university students in terms of their environmental knowledge, environmental attitude, and behavioral intentions. The results showed that the ecotourism perception of Chinese and Taiwanese university students affect their behavioral intentions. Chinese university students exhibited a higher correlation between ecotourism knowledge and behavioral intentions than their Taiwanese counterparts. The findings also revealed differences between the Chinese and Taiwanese students in their perception of ecotourism, and this disparity was particularly evident with regards to how ecotourism should be governed. A moderate difference in ecotourism behavioral intentions was also identified, in which Taiwanese university students were less likely to engage in self-empowerment or private empowerment, to be more educated in the field of ecotourism than their Chinese counterparts.
\end{abstract}

Keywords: behavioral studies; ecotourism; education; environmental attitudes; environmentally responsible behavior

\section{Introduction}

The tourism industry is commonly accepted as an 'industry without chimney' as it does not discharge significant amounts of harmful substances or smokes like other industries (e.g., manufacturing, construction) that can have a devastating impact on the environment [1]. However, the argument about the extent to which the effects of the tourism industry have on the environment has been subject to controversial debates. In recent years, there has been an increasing focus on tourism activities, and this is accompanied by an increase in the tourism population. However, a rapid growth in tourism affects the natural environment and the socio-cultural structures of those 
places [2,3]. Tourism growth relies on the environment of the tourism area being healthy. Since the beginning of 2002, which was the United Nation's International Year of Ecotourism, the global tourism industry has emphasized the growing importance of both sustainable and tourism development that aims at maximizing the economic, environmental, and social benefits from ecotourism $[4,5]$. Furthermore, people have sought to strike a balance between economic growth and environmental protection in order to avoid the drawbacks associated with mass tourism. According to the Goal 17: Revitalize the global partnership for sustainable development, as outlined in the United Nations Sustainable Development Goals (SDG) in 2015, tourism activities are urged to protect the natural environment and emphasize respect for natural heterogeneity, and thereby regard nature as an independent form of life. The 2017 World Tourism Day theme was also declared as 'Sustainable Tourism-a Tool for Development'. Therefore, in addition to passively ensuring that ecotourism will not destroy the environment, tourists can actively understand and enjoy the natural environment, and thus promote the behavior of 'conservation, education, and restoration' [6,7].

In East Asia, both China (People's Republic of China, PRC), which is home to one-fifth of the global population, and Taiwan, which is an island nation (Republic of China, ROC), promote ecotourism. China has, in the past decade, seen a significant growth in its tourism market and this was evident by the very high domestic (4.44 billion) and international inbound (138 million) tourist trips in 2016, which accounted for a revenue worth of CNY\$3.94 trillion and US\$120 billion, respectively. While China has a large number of attractions, such as historic sites and relics, economic hot spots, and culturally diverse places of interest, more recently there has been a focus towards ecotourism whereby the government aims to improve China's reputation for sustainable tourism. Some of the ecotourism destinations include: Changqing National Nature Reserve, Jiuzhaigou National Park, Changbai Mountains, and Kanas Lake. As for Taiwan, the tourism industry has been growing gradually over the past decade and the number of international visitors had reached a record high of 10.69 million in 2016. Accordingly, the Taiwan tourism sector is expected to be worth NT $\$ 1.2$ trillion by 2025 and is considered the backbone of the nation's economy. In recognition of the contributions made by this important sector, the government has undertaken significant amount of work towards quality tourism development and promotion, including ecotourism which was first embraced in 2002. Some of the ecotourism destinations include: Yangmingshan National Park, Sun Moon Lake, Taroko National Park, and Aboriginal Culture Village. While both countries share many similarities, particularly in traditional customs, cultures, and beliefs, because their political systems are at distinct stages of development, the environmental-governance behaviors, perceptions of ecotourism and the environmental education system at these two places are postulated to differ. Figure 1 shows the recent international inbound tourist trips to China and Taiwan.

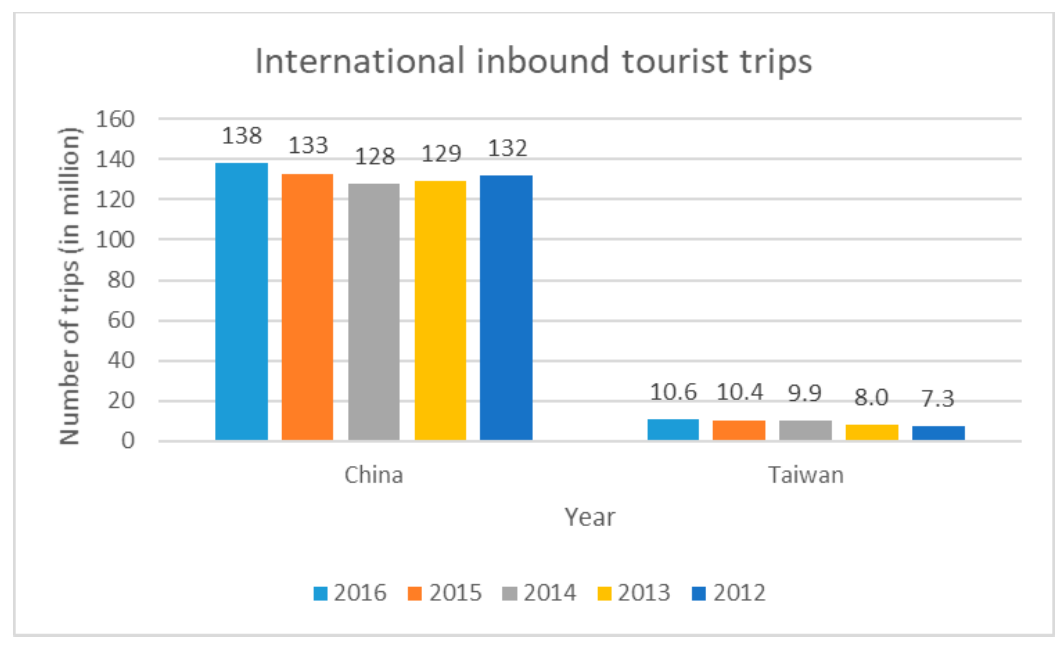

Figure 1. International inbound tourist trips. 
A review of the literature revealed that few scholars have previously studied the relationship between ecotourism and the education environment, which is the focus of this study [8,9]. This study seeks to investigate university students' environmental literacy on ecotourism in China and Taiwan, and aims to:

(1) understand the impact of the concept of ecotourism on Chinese and Taiwanese university students' environmental knowledge, environmental attitude, and behavioral intentions;

(2) explore the ecotourism factors that affect Chinese and Taiwanese university students' environmental knowledge, environmental attitude, and behavioral intentions;

(3) analyze and discuss the factors that facilitate or hinder the impact of ecotourism on environmental knowledge, environmental attitude, and behavioral intentions; and

(4) propose recommendations on introducing environmental education in universities.

\section{Literature Review}

\subsection{Ecotourism Courses}

The history of ecotourism is short, spanning no more than 50 years. During 1960-1970, the immigrant tourist populations in Europe and USA grew rapidly, and this has affected the ecosystems in national parks and protected areas in numerous countries worldwide. With the development of the environmental movement, people begin to examine the environmental and social impacts of tourism and started exploring how to use the nature and seek to balance tourism, environmental protection, and sustainable development. Hetzer [10] indicated that as leisure travel becomes a trend, tourism activities in developing countries have affected the ecological environment. Hetzer [10] also proposed the concept of 'ecological tourism', which has the following connotations: (1) minimal environmental impact; (2) minimal impact on, and maximal respect for, host cultures; (3) maximal economic benefits to host country's people at the grassroots level; and (4) maximal recreational satisfaction derived from participating in the tour. In the early 1980s, the travel industry noted the potential benefits of ecotourism, and has since leased or purchased land in remote areas, and introduced ecological itineraries and tour-guide services. Numerous countries have identified ecotourism as a mean to not only achieve the goals of environmental protection and national development, but also to provide notable benefits to local communities through the protection of community resources that enable sustainable development [11,12]. However, ecotourism cannot be sustainable if the tourism industry does not use the limited natural or cultural resources in specific locations wisely in the long term [12,13]. In 1983, Ceballos-Lascuráin (a Mexican architect), who coined the word 'ecotourism', had in 1981 started using the Spanish phrase 'turisimo ecológico' in order to express the ecotourism approach $[3,14]$. He considered ecotourism to be an alternative to mass tourism and is to be undertaken for the purpose of studying, enjoying, and experiencing the ecological environment in the absence of anthropogenic interference or contamination, with the goals being to promote local economic and ecological conservation [14]. Since the 1990s, ecotourism has emerged as a concept of environmental literacy and innovative business, and it has included adventure tourism, alternative tourism, environment-friendly travel, ethical tourism, green tourism, nature tourism, nature-oriented tourism, responsible tourism, soft tourism/tourisme doux, and sustainable tourism [15,16]. Honey [11] defines ecotourism as "responsible travel to natural areas which conserves the environment and improves the welfare of local people." She has noted the promotion of ecotourism for economic development by non-industrialized countries in the early 1990s. For example, the former Soviet Union, Eastern Europe, China, and Vietnam, which once tightly controlled tourism, are now on the bandwagon (p. 18) [11]. Debates in previous studies on how ecotourism can be used to promote democratic reforms and human rights have resulted in an extended definition: "Ecotourism is travel to fragile, pristine, and usually protected areas that strives to be low impact and (usually) small scale. It helps educate the traveler; provides funds for conservation; directly benefits the economic 
development and political empowerment of local communities; and fosters respect for different cultures and for human rights" (p. 25) [11].

To date, only a few studies have focused on ecotourism that investigate tourists' political empowerment and human rights [17]. However, Hungerford and Volk [18] declared that empowerment variables are crucial in the training of environmental responsible citizens. Furthermore, few studies have also investigated the relationship between environmental literacy and ecotourism activities. Roth and Teksoz et al. considered environmental literacy to include ability, knowledge, skills, and actions that can be defined using behavioral intentions [19,20]. Environmental literacy refers to people's knowledge associated with environmental matters, their positive environmental attitudes and values, and the skills, motivation, and commitment required to participate in solving environmental problems [21,22]. This actively enables the environment movement in maintaining balance between the environment and the quality of life.

Ecotourism was first introduced in a few Chinese universities as a major study in the early 1990s. Since then, the number of Chinese universities (e.g., Peking University, Beijing, China, Shanghai Jiao Tong University, Shanghai, China) offering ecotourism as a specialization or an elective course (e.g., ecotourism principles) has increased, but it is still not a course that is commonly taught and undertaken. On the other hand, the concept of ecotourism was dated back to the late 1980s in Taiwan and its importance has grown considerably over the years. In recognizing the significant contribution of ecotourism to the tourism industry, many universities (e.g., TransWorld University, Douliu, Taiwan, National Taiwan Normal University, Taipei, Taiwan) have established disciplinary areas and departments of tourism, business, and environmental sciences that offer ecotourism as a major study, as well as an elective course (e.g., ecotourism and sustainable development). The increasing offerings of ecotourism courses at universities in China and Taiwan align closely to the respective governments' effort and acknowledgement towards the growing significance of ecotourism.

\subsection{Ecotourism Knowledge}

According to the definition that governmental bodies, scholars, experts, and private conservation groups have attempted to construct from 1960 until now, ecotourism refers not only to the enjoyment of the beautiful ecological landscape situated within tourism areas, it also emphasizes the evolution of environmental conservation behavior and thinking patterns [23,24]. This mode of progression from thinking to action has been developed as an attempt to protect the quality of tourism resources through ecological protection. The goal is to ensure that tourism activities are long-lasting and can maintain the ecological environment, social culture, local economy, and a balanced development of sustainable tourism. Moreover, this process deepens our understanding of the local natural environment, people, and the social and traditional culture in natural areas. Thus, studies conducted by ecological and tourism scholars show that the conditions that facilitate ecotourism are based on the natural environment (including the aboriginal culture). The function of ecotourism is to protect the environment and enable sustainable local development, which can achieve common benefits for all stakeholders (e.g., regional ecological managers, community residents, local tourism operators, and tourists) [25].

To target the ecological traits of people who visit tourism destinations, tourists are provided with recreational experiences that guide their environmental awareness. However, this may not produce responsible tourism behavior [26]. Many studies $[27,28]$ showed that environmentally friendly attitudes do not necessarily lead to eco-friendly behaviors. These experiences from environmentally friendly behaviors should be regarded as 'necessary conditions' of ecotourism. In Asia, during the period when authoritarian states are being transformed into democratic states, few people engage in participating tourism in developing countries [29]. In this study, the governance of tourism was included, which is a form of tourism management that is based on the policies that Asian countries use in managing ecotourism areas. According to the norms and the legal system of ecotourism established by these 
nations, investment funds are input to strengthen the tourism governance manpower. In considering the aforementioned work, this study regards ecotourism to be a composition of the following:

(1) Responsible tourism: This type of tourism focuses on the responsibility of the people visiting natural areas to respect the local ecological environment, social culture, and traditional economy and to preserve local monuments [30,31].

(2) Educational tourism: This is focused on providing education to enhance people's environmental knowledge, inducing people to develop favorable attitudes toward the environment, and making them take environmental actions to reduce the impact of tourism [32,33].

(3) Participating tourism: This type of tourism focuses on participation, which allows tourists to give something back to the local economy, improves the well-being of local residents, and encourages all stakeholders to join in brainstorming $[7,25,29]$.

(4) Governing tourism: This deals with management units that provide environmental governance strategies, programs, and plans, and invest funds and manpower in order to improve the local tourism environment $[34,35]$.

Given the above, this study seeks to investigate participants' understanding of ecotourism, level of awareness and perception, and judgment or evaluation, and the proposed 'knowledge' dimension of ecotourism, which is the first dimension of environment literacy. The definition of environmental knowledge adopted in this study is the mental process of acquiring understanding through thought, experience, and the senses [36,37]. Thus, environmental knowledge contains the understanding of knowledge of ecotourism through thought, experience, and the senses from self-directed and school learning. Based on the literature reviewed, the knowledge dimension of ecotourism includes: responsible tourism, educational tourism, participating tourism, and governing tourism. Environmental-knowledge education is provided in order to develop environmental awareness through interactions between humans and the environment. This results in an appreciation, and exploration of the environment, which help people to be more aware of and acknowledge the existence of environmental problems.

\subsection{Attitudes toward Ecotourism}

Environmental literacy incorporates the dimensions of knowledge, attitude, and behavior. Diverse opinions exist regarding attitude, but it commonly includes the results of knowledge and learning processes, reactions to the feeling or perception of liking or disliking something, and judgment factors [38]. Hines et al. considered attitude to be a combination of people's views regarding the environment and matters that are part of a specific case related to the entire environment [39]. In this study, attitude is considered to be a dimension of the ecotourism. This study seeks to investigate participants' beliefs, values, and sentiments toward ecotourism, including their subjective judgment or evaluation.

\subsection{Behavioral Intentions toward Ecotourism}

Hines et al. identified certain environmental behavior patterns [39]. A major factor that elicits environmental behavior is people's intention to act, and therefore intention is the most favorable variable that influences action [30,40]. Furthermore, studies have also demonstrated that intentions related to environmental protection can explain the observed behavior of people [41,42]. Hungerford and Peyton proposed that environmental behavior can be classified into five categories: (1) persuasion; (2) consumer/economic action; (3) eco-management; (4) legal action; and (5) political action. Environmental behavior is measured here at the 'skill' level [43]. Behavioral practices that are observed in daily life can prevent the deterioration of the environment, and therefore environmental education, are critical to the development towards environmental behavior. In order to measure environmental behavior, behavioral intentions need to be measured. This study focuses on the students' behavioral intentions related to ecological management within the studied ecotourism area. 
Ecological management is presented as the third dimension of behavioral intentions, and based on the literature, it includes private empowerment (i.e., empowered personal capabilities), private action (i.e., personal action for privilege in private areas), and public service.

Previous studies related to this area have shown that environmental knowledge, environmental attitude, and environmental behavior are positively related to each other [44,45]. In examining the structure of environmental literacy, the assumption in most studies has been that environmental knowledge affects environmental attitude, and the attitude affects environmentally friendly behavior. However, only few studies have assumed and directly confirmed that knowledge and attitude of the environment affect environmentally friendly behavior, which this study aims to further explore [46].

\subsection{Relationship between Environmental Knowledge and Environmental Attitude}

Pooley and O'Connor considered attitude domains to be affected by the knowledge domain [47]. Specifically, the likelihood of change is affected by a person's stance toward knowledge or what Kruglanski described as 'epistemic motives'. Based on the definition of McKechnie, attitude is the composition of beliefs, values, and sentiments [38,48]. Here, the affective dimension of attitude deals with the emotional and non-emotional reactions toward the state of the environment (e.g., values, or likes/dislikes) [49]. Hence, the following hypothesis will be investigated in this study.

Hypothesis 1. Environmental knowledge positively affects environmental attitude.

\subsection{Relationship between Environmental Knowledge and Environmental Behavioral Intentions}

Hines et al. performed a meta-analysis on environmental behavior where the results indicate that people who understand environmental concerns and know how to act in response to such concerns tend to exhibit the attitude required to engage in environmentally responsible behaviors $[39,50]$. Kaiser et al. [46] reported that environmental knowledge and environmental values explained $40 \%$ of the variance of ecological behavioral intentions. Bamberg [50] also suggested that situation-specific knowledge are direct determinants of specific behaviors. Based on these studies, the second hypothesis is proposed as follow:

Hypothesis 2. Environmental knowledge positively affects environmental behavioral intentions.

\subsection{Relationship between Environmental Attitude and Environmental Behavioral Intentions}

Grob [51] indicateed that 39\% of the variance in environmental behavior can be explained by attitudinal components. Pooley and $\mathrm{O}^{\prime}$ Connor [47] also reported that values and attitudes affect environmentally conscious behaviors, and that changing environmental attitudes, emotions, and beliefs are more important than accumulating environmental related knowledge for influencing behaviors. Best and Mayerl [52] used traditional path analysis and latent structural equation modelling to test the hierarchical structure of environmental values, beliefs, attitudes, and their contribution to explaining recycling behavior, which conclude the direct effects of specific attitudes on behavior. This leads to the development of the third hypothesis as follows:

Hypothesis 3. Environmental attitude positively affects environmental behavioral intentions.

Using the above assumptions, a theoretical framework (Figure 2) is proposed for this study to investigate the relationships between environmental knowledge, environmental attitude, and behavioral intentions on ecotourism. 


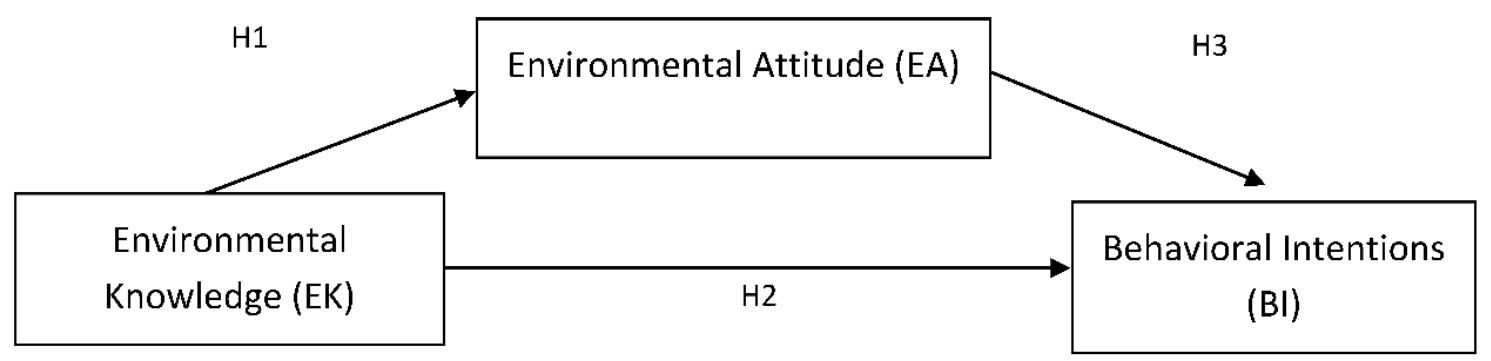

Figure 2. Hypothetical structure of environmental concern, H1: Environmental knowledge $\rightarrow$ Environmental attitude (Environmental knowledge has a positive impact on environmental attitude); H2: Environmental knowledge $\rightarrow$ Behavior intentions (Environmental knowledge has a positive impact on environmental behavioral intentions); H3: Environmental attitude $\rightarrow$ Behavior intentions (Environmental attitude has a positive impact on environmental behavioral intentions).

\section{Materials and Methods}

\subsection{Research Areas and Participants}

This study was conducted at two locations; People's Republic of China (P. R. China), and Republic of China (Taiwan, ROC). The participants of the study consisted of first-, second-, third-, and fourth-year undergraduate students in China and Taiwan, age between 18 to 23 years old. The students were from a diverse study background, including disciplinary areas in natural sciences and social sciences. Based on the geographic (i.e., north, east, south, and west regions) and demographic (size of universities) stratum, a stratified random sampling technique was used to select four universities each from China and Taiwan. The survey was conducted over an extended period from March 2011 to March 2014, and this was due to limited resources and the extensive geographical distances to be covered in China. The rationale for selecting the sample was primarily because they were considered being at a critical life stage to self-shaping their environmental knowledge, affective values, and environmental behavior from their environmental identity and decision-making process [53].

A total of 1200 questionnaires were equally distributed and surveyed at the selected universities in China and Taiwan during 2011 to 2014. Of which, 835 (69.5\%) valid questionnaires were returned, with China accounted for 420 and the remaining 415 were from Taiwan. Written consent forms were sent to class teachers and students to obtain their agreement to participate in this cross-national research study and inform them of their rights to withdraw at any time. The questionnaire survey was conducted in the classroom setting at the respective classes (50 in China and 48 in Taiwan) after permissions to participate had all been received. The participants had approximately 10 min to listen to relevant instructions and the opportunity to seek any clarifications (including Honey's definition of ecotourism) prior to completing the 30 min questionnaire in class.

\subsection{Instrument and Instrumentation}

When designing these questionnaire items, the following steps were undertaken to select ecotourism and environmental literacy instrument with consideration given to the alignment of the contextual issues. This study was based on a substantial consequence of literature reviews demonstrating the knowledge and attitudinal aspects of environmental behavioral research. Reference to previous studies related to knowledge, attitude, and behavioral intentions was attempted to explore the causal relationships.

The item analysis in terms of difficulty and discriminating the knowledge items for "yes/no" answers required the knowledge category to be changed to students' understanding through thought, experience, and the senses. The compiled pools of items were selected from the following steps [54]: 
- Step 1: More than 25 research papers and documents related to ecotourism and environmental literacy in China, Taiwan, and abroad [55-59] were reviewed to establish these item pools.

- Step 2: The items in the pools were selected in accordance to the research objectives guided by the definition of each element and associated components. The initial compiled questions items were then prepared for panel review from seven experts.

- Step 3: The initially-compiled question items were given to a panel of seven experts (three from China, four from Taiwan) from different areas of specialization, such as tourism, psychology, geography, sociology, biology, ecology, and environmental education for their formal review and expert opinions. The experts were required to assess the items on their appropriateness, relevance, and language used from which content validity had to be reached. Each question item had received at least $80 \%$ agreement by the experts.

- Step 4: The instrument was revised based on the experts' opinions and feedback, and subsequently pre-tested with 40 (20 each from China and Taiwan) randomly selected undergraduate students. The final questionnaire survey consisted of two main sections; (1) demographic items; and (2) environmental literacy and ecotourism assessment items. However, the questionnaire content (measures) had been rearranged so that they were well blended into the three key domain areas of knowledge, attitude, and behavioral intentions (see Appendix A). A five-point Likert scale (i.e., $1=$ "Strongly disagree" to $5=$ "Strongly agree") was adopted for the measurement. The following process was used to construct the factor dimensions and the measurement questions related to ecotourism environmental literacy. Therefore, this study specifically sought to measure two key dimensions: (1) knowledge; (2) attitude, that were considered influential to environmental behavioral intentions. Three factor dimensions (i.e., knowledge, attitude, and behavioral intentions) were identified with 38 measurement questions developed.

\subsection{Measures}

Next, Statistical Package for the Social Sciences (SPSS 22.0) statistical software was used to conduct the descriptive analysis and the reliability analysis of the samples before using structural equation modelling to perform confirmatory factor analysis. Frequency analysis was used to determine the total number of occurrences, the mean and standard deviation (SD) scores for the demographic questions and items in the key dimensions. The Pearson Correlation technique was used to measure the strength and direction of relationship that exists between these key dimensions. The multiple regression analysis was used to predict the influence of attitude on environmental behaviors.

\section{Results}

\subsection{Descriptive Statistics}

As shown in Table 1, majority $(60.8 \%)$ of the participants were female with the remaining $39.2 \%$ being male. There were more male participants in China (40.7\%) than in Taiwan (37.6\%), whereas female participants in Taiwan (62.4\%) accounted for a higher proportion than in China (59.3\%). Most of the participants were fourth-year undergraduate students (31.6\%), and this was followed by first-year $(28.7 \%)$, second-year $(21.1 \%)$, and third-year (18.6\%) undergraduate students. In China, 35.5\% were fourth-year undergraduate students, while majority of the participants in Taiwan were represented by first-year (34.9\%) undergraduate students. 
Table 1. Gender and year level of participants.

\begin{tabular}{ccccccc}
\hline & \multicolumn{2}{c}{ China } & \multicolumn{2}{c}{ Taiwan } & \multicolumn{2}{c}{ Total } \\
\cline { 2 - 7 } & Frequency & Percentage & Frequency & Percentage & Frequency & Percentage \\
\hline Gender & & & & & & \\
Male & 171 & 40.7 & 156 & 37.6 & 327 & 39.2 \\
Female & 249 & 59.3 & 259 & 62.4 & 508 & 60.8 \\
Year level & & & & & & \\
First-year & 95 & 22.6 & 145 & 34.9 & 240 & 28.7 \\
Second-year & 89 & 21.2 & 87 & 21.0 & 176 & 21.1 \\
Third-year & 87 & 20.7 & 68 & 16.4 & 155 & 18.6 \\
Fourth-year & 149 & 35.5 & 115 & 27.7 & 264 & 31.6 \\
\hline
\end{tabular}

In relation to the question "How many travel days have you ever engaged in domestic tourism in the last year?", the findings (as shown in Figure 3) showed that a one-day trip was considered as most common in 'travel days' by 370 participants (44.3\%), while a four-day trip (85 participants, $10.2 \%$ ) was regarded as the least common. A comparison between Chinese and Taiwanese students revealed a notable difference in their travel days. While majority of the Taiwanese students (277 participants, $66.7 \%$ ) engaged in a one-day trip, the travel days for Chinese students were more evenly spread across (i.e., ranging from a one-day trip to a five-day or more trip).

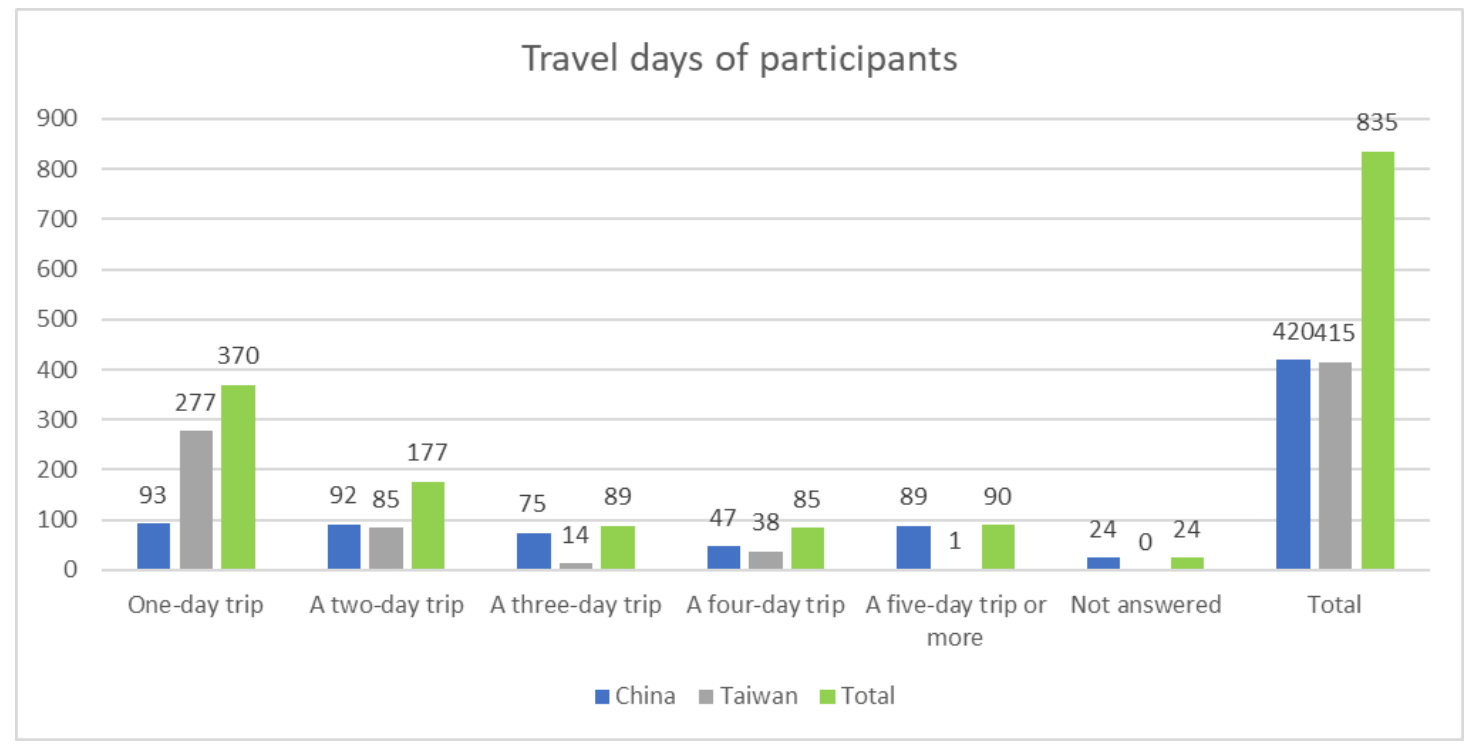

Figure 3. Travel days of participants.

With regards to the question "Which travel period did you choose to engage in domestic tourism in the last year?", results (as shown in Figure 4) indicated that more than half of the participants (435 participants, 52.1\%) would travel during Spring and Summer holidays, and this was followed by weekends (188 participants, 22.5\%), Golden Week (continuous holidays) (114 participants, 13.7\%), and weekdays (77 participants, 9.2\%). Although both the Chinese and Taiwanese students agreed that they were most likely to travel during the period of Spring and Summer holidays, they differed in their responses about travelling during weekends and Golden Week (continuous holidays). Approximately $26.8 \%$ of the Chinese students (112 responses) favored travelling during the Golden Week (continuous holidays), while Taiwanese students (154 participants, 37.1\%) preferred travelling during weekends.

In terms of the question about ecotourism participation "Have you ever participated in ecotourism activities?", the findings (as shown in Figure 5) suggested that majority (64.9\%) of the participants (542 responses) had not participated in any ecotourism activities, while the remaining 35.1\% (293 participants) had some level of participation. The results also revealed a high proportion 
(374 participants, $89 \%$ ) of the Chinese students who had not participated in any ecotourism activities, with only a marginal 11\% (46 responses) indicated their involvement in such activities. In contrast, $247(60 \%)$ Taiwanese students had responded to having participated in ecotourism activities, and $40 \%$ (168 participants) responded with no participation. This suggested that Taiwanese students had a greater level of participation in ecotourism activities than their Chinese counterparts.

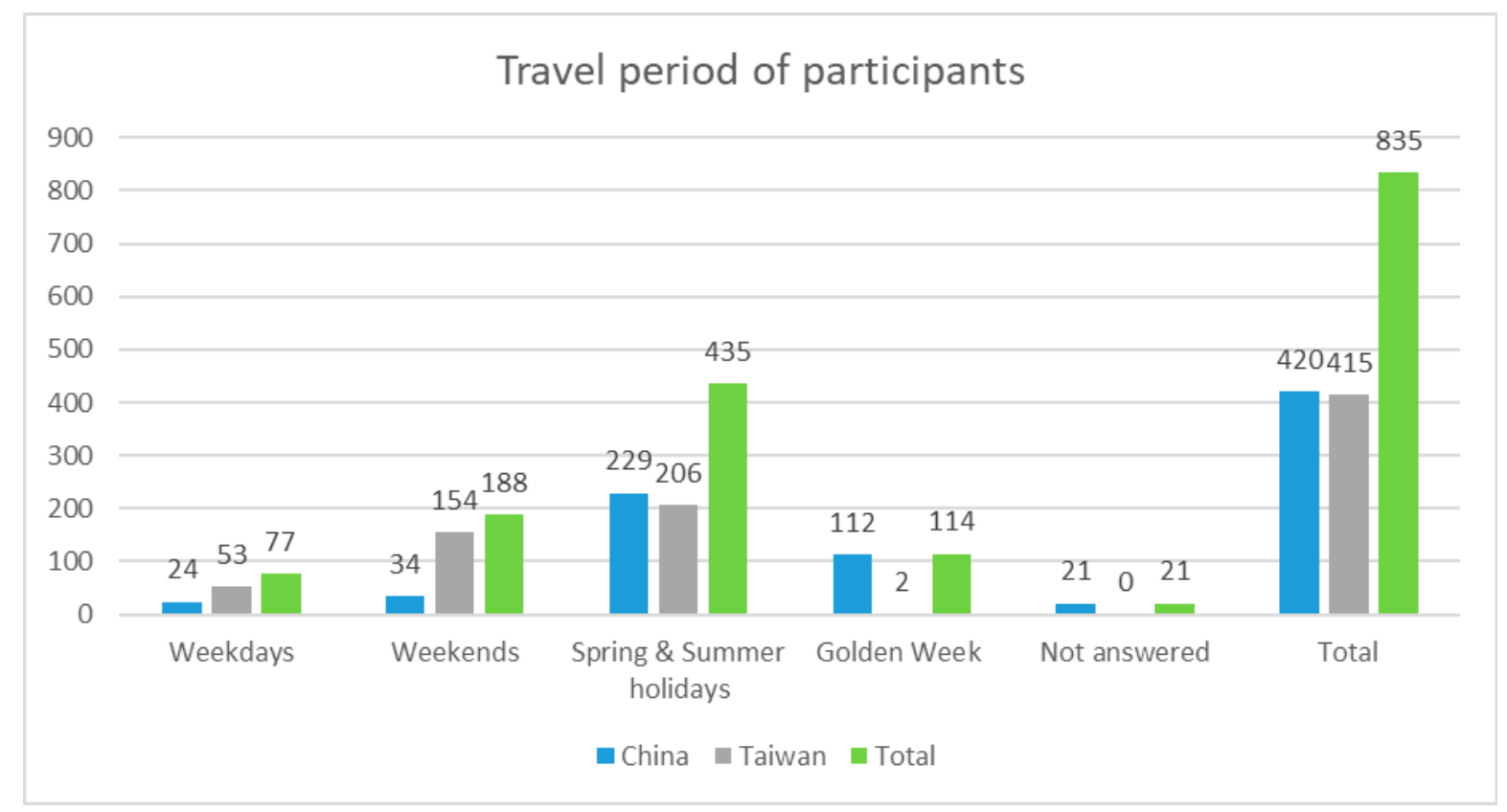

Figure 4. Travel period of participants.

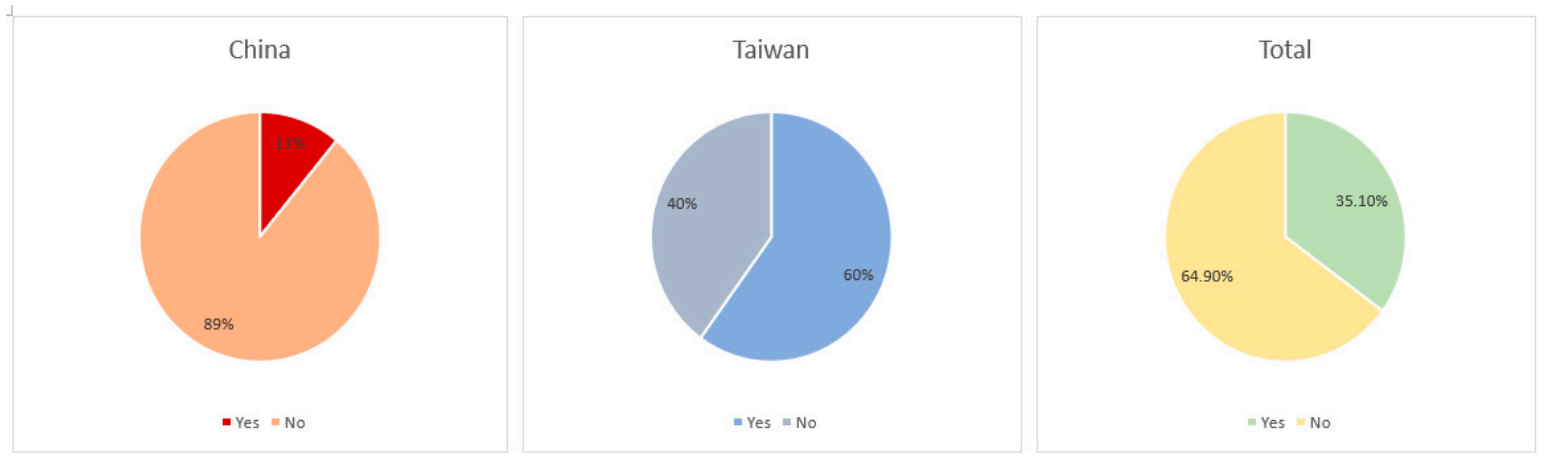

Figure 5. Ecotourism participation.

In response to the question "Have you ever learn the concepts of ecotourism at school?" about learning the concepts of ecotourism as a part of their university curricula, the results (as shown in Figure 6) showed that $540(64.7 \%)$ participants agreed that they had been taught the concepts of ecotourism, with the remaining 35.3\% (295 participants) suggested that such knowledge had not been taught at their university. The findings revealed a higher proportion of Taiwanese students (329 responses, 79.5\%) had been taught the concept of ecotourism at university than the Chinese students (211 responses, $50.2 \%$ ). This could possibly indicate a greater level of emphasis on teaching the concepts of ecotourism as part of the university curricula in Taiwan than those in China. 


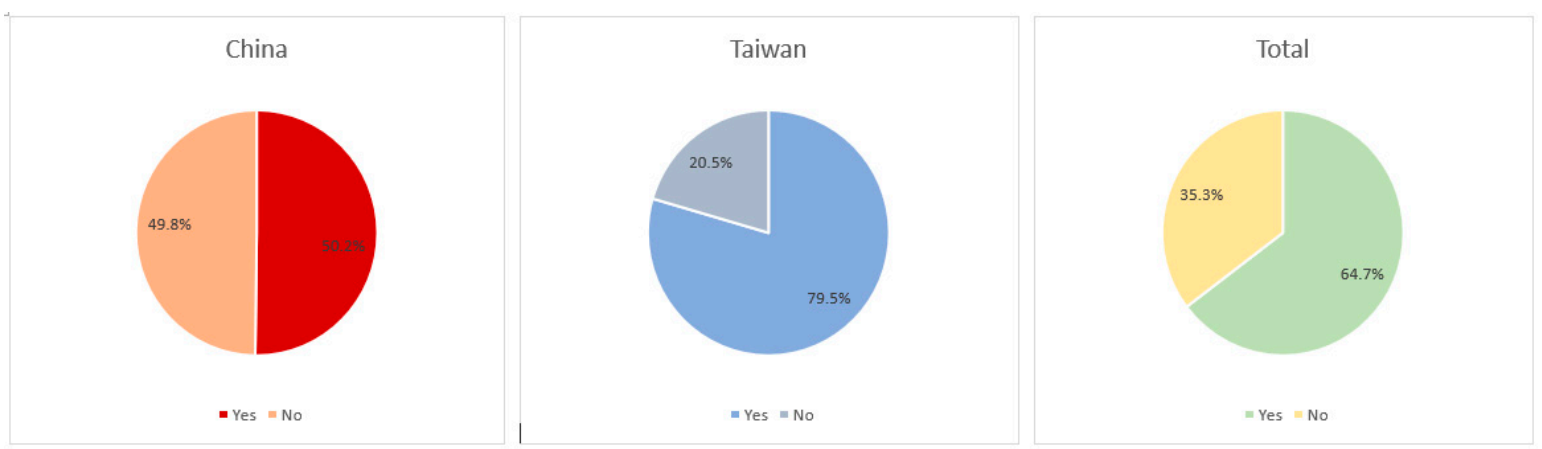

Figure 6. Learn the concepts of ecotourism at school.

In terms of the effects of the gender variable on knowledge, attitude, and behavioral intentions, the overall findings revealed significant differences between females and males in their knowledge $(\mathrm{df}=833$, two-tailed, $t=3.801>1.967, p=0.000)$, attitude $(\mathrm{df}=833$, two-tailed, $t=4.476>1.967, p=0.000)$ and behavioral intentions ( $\mathrm{df}=833$, two-tailed, $t=2.745>1.967, p=0.006)$. Results also suggested that there were significant differences between females and males in China about their knowledge ( $\mathrm{df}=418$, two-tailed, $t=3.070>1.967, p=0.002)$, attitude ( $\mathrm{df}=418$, two-tailed, $t=2.238>1.967$, $p=0.026)$ and behavioral intentions ( $\mathrm{df}=418$, two-tailed, $t=2.966>1.967, p=0.018$ ). Whereas in Taiwan, significant differences between females and males existed in their knowledge $(\mathrm{df}=413$, two-tailed, $t=2.593>1.967, p=0.010)$, attitude $(\mathrm{df}=413$, two-tailed, $t=4.044>1.967, p=0.000)$. Table 2 below provides a brief summary about the effects of the gender variable on knowledge, attitude, and behaviors intentions.

Table 2. The effects of the gender variable on knowledge, attitude, and behavioral intentions.

\begin{tabular}{|c|c|c|c|c|c|c|c|c|c|c|c|c|}
\hline \multirow{2}{*}{ Gender } & \multicolumn{4}{|c|}{ Knowledge } & \multicolumn{4}{|c|}{ Attitude } & \multicolumn{4}{|c|}{ Behavioral Intentions } \\
\hline & Mean & SD & $t$ & $p$ & Mean & SD & $t$ & $p$ & Mean & SD & $t$ & $p$ \\
\hline \multicolumn{13}{|l|}{ Total } \\
\hline Female & 3.83 & 0.45 & \multirow{2}{*}{3.801} & \multirow{2}{*}{0.000} & 4.03 & 0.39 & \multirow{2}{*}{4.476} & \multirow{2}{*}{0.000} & 3.21 & 0.47 & \multirow{2}{*}{2.745} & \multirow{2}{*}{0.006} \\
\hline Male & 3.72 & 0.43 & & & 3.90 & 0.46 & & & 3.12 & 0.47 & & \\
\hline \multicolumn{13}{|l|}{ China } \\
\hline Female & 3.91 & 0.47 & \multirow{2}{*}{3.070} & \multirow[b]{2}{*}{0.002} & 4.04 & 0.33 & \multirow{2}{*}{2.238} & \multirow[b]{2}{*}{0.026} & 3.37 & 0.46 & \multirow{2}{*}{2.966} & \multirow{2}{*}{0.003} \\
\hline Male & 3.78 & 0.38 & & & 3.95 & 0.41 & & & 3.23 & 0.44 & & \\
\hline \multicolumn{13}{|l|}{ Taiwan } \\
\hline Female & 3.76 & 0.43 & \multirow{2}{*}{2.593} & \multirow{2}{*}{0.010} & 4.03 & 0.43 & \multirow{2}{*}{4.044} & \multirow{2}{*}{0.000} & 3.05 & 0.42 & \multirow{2}{*}{1.496} & \multirow{2}{*}{0.136} \\
\hline Male & 3.64 & 0.47 & & & 3.84 & 0.51 & & & 2.98 & 0.46 & & \\
\hline
\end{tabular}

As for the effects of the participants' year level at the university on knowledge, attitude, and behavioral intentions, the overall results indicated that there were no significant differences between all the different year levels on knowledge, attitude, and behavioral intentions. However, the findings for the Chinese participants suggested that there existed significant differences between different year level of undergraduate students on behavioral intentions ( $\mathrm{df}=418$, two-tailed, $F=3.691>1.967, p=0.012$ ). With regards to the Taiwanese participants, the findings indicated significant differences between different year level of undergraduate students on knowledge ( $\mathrm{df}=413$, two-tailed, $F=2.674>1.967$, $p=0.047)$ and behavioral intentions ( $\mathrm{df}=413$, two-tailed, $F=2.639>1.967, p=0.049)$. A brief summary about the effects of the year level variable on knowledge, attitude, and behaviors intentions is provided in Table 3 below. 
Table 3. The effects of the year level variable on knowledge, attitude, and behavioral intentions.

\begin{tabular}{|c|c|c|c|c|c|c|c|c|c|c|c|c|}
\hline \multirow{2}{*}{ Year Level } & \multicolumn{4}{|c|}{ Knowledge } & \multicolumn{4}{|c|}{ Attitude } & \multicolumn{4}{|c|}{ Behavioral Intentions } \\
\hline & Mean & SD & $F$ & $p$ & Mean & SD & $F$ & $p$ & Mean & SD & $F$ & $p$ \\
\hline \multicolumn{13}{|l|}{ Total } \\
\hline First-year & 3.76 & 0.55 & \multirow{4}{*}{1.654} & \multirow{4}{*}{0.176} & 3.97 & 0.44 & \multirow{4}{*}{0.628} & \multirow{4}{*}{0.597} & 3.16 & 0.50 & \multirow{4}{*}{1.253} & \multirow{4}{*}{0.289} \\
\hline Second-year & 3.75 & 0.42 & & & 3.96 & 0.42 & & & 3.12 & 0.42 & & \\
\hline Third-year & 3.80 & 0.36 & & & 3.96 & 0.42 & & & 3.19 & 0.45 & & \\
\hline Fourth-year & 3.83 & 0.41 & & & 4.00 & 0.41 & & & 3.20 & 0.49 & & \\
\hline \multicolumn{13}{|l|}{ China } \\
\hline First-year & 3.92 & 0.64 & \multirow{4}{*}{1.011} & \multirow{4}{*}{0.388} & 3.40 & 0.40 & \multirow{4}{*}{0.843} & \multirow{4}{*}{0.471} & 3.43 & 0.46 & \multirow{4}{*}{3.691} & \multirow{4}{*}{0.012} \\
\hline Second-year & 3.82 & 0.36 & & & 3.40 & 0.37 & & & 3.26 & 0.41 & & \\
\hline Third-year & 3.83 & 0.35 & & & 3.96 & 0.40 & & & 3.22 & 0.44 & & \\
\hline Fourth-year & 3.86 & 0.36 & & & 4.04 & 0.32 & & & 3.33 & 0.48 & & \\
\hline \multicolumn{13}{|l|}{ Taiwan } \\
\hline First-year & 3.65 & 0.44 & \multirow{4}{*}{2.674} & \multirow{4}{*}{0.047} & 3.96 & 0.46 & \multirow{4}{*}{0.142} & \multirow{4}{*}{0.935} & 2.98 & 0.44 & \multirow{4}{*}{2.639} & \multirow{4}{*}{0.049} \\
\hline Second-year & 3.68 & 0.48 & & & 3.93 & 0.47 & & & 2.98 & 0.40 & & \\
\hline Third-year & 3.76 & 0.36 & & & 3.96 & 0.46 & & & 3.15 & 0.46 & & \\
\hline Fourth-year & 3.79 & 0.46 & & & 3.97 & 0.50 & & & 3.05 & 0.45 & & \\
\hline
\end{tabular}

\subsection{Data Analysis of Study Variables}

Structural equation modelling was used to validate the measurement model and the structural model. Prior to conducting the modelling measurement, the data on the research variables were analyzed. The structural equation estimation is affected by the distribution properties of variables, and thus the distribution of variables must be tested first. According to the argument of Kline [60], when the absolute value of the skewness of a variable is $>3$, the value can be regarded as being an extreme value; in the case of kurtosis, absolute values $>10$ are considered extreme values $[40,56]$. If these problems are created by the skewness and kurtosis values, bias will be produced when the maximum-likelihood method is used for estimating correlation coefficients. If the coefficient lies within the aforementioned ranges, the bias of the estimated coefficient is considered acceptable. As such, each dimension's skewness and kurtosis values was calculated, and the results are presented in Table 4 . In the three dimensions of the research variables, the absolute values of maximal skewness and maximal kurtosis were 1.084 and 1.521, respectively; thus, in terms of the argument of Kline [60], extreme values were not measured.

When examining the Chinese and Taiwanese students' environmental knowledge, environmental attitude, and behavioral intentions, the findings (as shown in Table 4) showed that Chinese students had exceeded the mean values of 3.50 for all three dimensions, i.e., environmental knowledge $(3.966 \pm 0.393)$, environmental attitude $(4.229 \pm 0.486)$, behavioral intentions $(3.713 \pm 0.564)$. Conversely, the Taiwanese students only had the environmental attitude dimension ( $3.834 \pm 0.478)$ exceed the mean value 3.50. In the three dimensions of environmental knowledge, environmental attitude, and behavioral intentions, the mean values measured in the case of Chinese students were higher than those measured in the case of Taiwanese students. Refer to Appendix A for the list of questions asked in the survey for these three dimensions.

Table 4. Test value of the data of the study variables.

\begin{tabular}{ccccccccc}
\hline & \multicolumn{4}{c}{ China } & \multicolumn{4}{c}{ Taiwan } \\
\cline { 2 - 10 } & Mean & SD & Skewness & Kurtosis & Mean & SD & Skewness & Kurtosis \\
\hline Environmental knowledge & 3.966 & 0.393 & -0.265 & 0.532 & 2.620 & 0.253 & -0.124 & 0.362 \\
\hline Environmental attitude & 4.2294 & 0.486 & -1.084 & 1.521 & 3.834 & 0.479 & -0.564 & -0.382 \\
\hline Behavioral intentions & 3.713 & 0.564 & -0.458 & 0.208 & 2.924 & 0.456 & -0.069 & -0.008 \\
\hline
\end{tabular}




\subsection{Confirmatory Factor Analysis}

Confirmatory factor analysis was performed mainly to understand the state of the fit between each item of a scale and the measurement questions. The following conventional goodness-of-fit criteria was recorded in order to evaluate the model [47-49]. Chinese students: Goodness of Fit Index (GFI) $=0.96$, Comparative Fit Index $(\mathrm{CFI})=0.94$, Non-Normed Fit Index $(\mathrm{NNFI})=0.92$, the standardized root mean square residual $(S R M R)=0.056$, the root mean square error of approximation $($ RMSEA $)=0.075$; and Taiwanese students: GFI $=0.96, \mathrm{CFI}=0.89, \mathrm{NNFI}=0.84$, SRMR $=0.061, \mathrm{RMSEA}=0.068$. The measured criteria reveal that the test results are in line with the criteria used for these indicators [60-62].

\subsection{Testing the Research Hypotheses}

The maximum-likelihood estimation method was used to estimate the path coefficients of the theoretical model, and also to test each of the hypotheses proposed. Accordingly, a sample size of 100 to 150 is considered most suitable for use in the maximum-likelihood estimation method when used in structural modelling [63]. As the number of valid samples collected was 420 in the case of Chinese students and 415 in the case of Taiwanese students, therefore the sample size is considered appropriate for the use of the estimation methods.

According to the path analysis, results (as shown in Table 5) revealed that Hypotheses 1 and 2 were supported in the case for the Chinese students, which indicated that environmental knowledge had positive impact on environmental attitude, and environmental knowledge also had a positive impact on environmental behavioral intentions. On the other hand, findings for the Taiwanese students showed that environmental knowledge had a positive impact on environmental behavioral intentions, and environmental attitude also had a positive impact on environmental behavioral intentions. Therefore, Hypotheses 2 and 3 were both accepted.

Table 5. The result of test for path analysis.

\begin{tabular}{ccccccccc}
\hline \multirow{2}{*}{ Path } & \multicolumn{4}{c}{ China } & \multicolumn{5}{c}{ Taiwan } \\
\cline { 2 - 9 } & Standard Error & $t$-Value & Significant & Result & Standard Error & $t$-Value & Significant & Result \\
\hline H1: EK $\rightarrow$ EA & 0.75 & 5.50 & ${ }^{* * *}$ & Support & -0.62 & 6.85 & ${ }^{* * *}$ & Non-support \\
\hline H2: EK $\rightarrow$ BI & 0.76 & 2.31 & ${ }^{* * *}$ & Support & 0.16 & 1.26 & ${ }^{* * *}$ & Support \\
\hline H3: $\mathrm{EA} \rightarrow \mathrm{BI}$ & -0.42 & -1.10 & ${ }^{* * *}$ & Non-support & 0.21 & 1.36 & ${ }^{* * *}$ & Support \\
\hline
\end{tabular}

\subsection{Relationships between Environmental Knowledge, Environmental Attitude, and Behavioral Intentions}

Table 6 lists the total and indirect effects obtained as the output measured using LISREL 8.80, and Figures 7 and 8 show the results of the structural modelling path analysis.

Table 6. Total and indirect effects between environmental knowledge, environmental attitude, and behavioral intentions.

\begin{tabular}{|c|c|c|c|c|c|c|c|c|c|}
\hline & \multirow{3}{*}{ Effect } & \multicolumn{4}{|c|}{ China } & \multicolumn{4}{|c|}{ Taiwan } \\
\hline & & \multicolumn{2}{|c|}{ Environmental Attitude } & \multicolumn{2}{|c|}{ Behavioral Intentions } & \multicolumn{2}{|c|}{ Environmental Attitude } & \multicolumn{2}{|c|}{ Behavioral Intentions } \\
\hline & & Effect & $t$-Value & Effect & $t$-Value & Effect & $t$-Value & Effect & $t$-Value \\
\hline Environmental knowledge & $\begin{array}{c}\text { Indirect } \\
\text { effect }\end{array}$ & & & -0.32 & -1.05 & & & & \\
\hline \multirow{3}{*}{ Environmental attitude } & $\begin{array}{l}\text { Direct } \\
\text { effect }\end{array}$ & & & -0.42 & -1.10 & & & 0.21 & 1.36 \\
\hline & $\begin{array}{c}\text { Indirect } \\
\text { effect }\end{array}$ & & & & & & & & \\
\hline & $\begin{array}{l}\text { Total } \\
\text { effect }\end{array}$ & - & - & -0.42 & -1.10 & - & - & 0.21 & 1.36 \\
\hline
\end{tabular}


Results indicated that, in the case of Chinese students, there was a significant positive-impactrelationship existed between environmental knowledge and environmental attitude and between environmental knowledge and behavioral intentions. On the other hand, in the case of Taiwanese students, there existed a significant positive-impact-relationship between environmental knowledge and behavioral intentions and between environmental attitude and behavioral intentions.

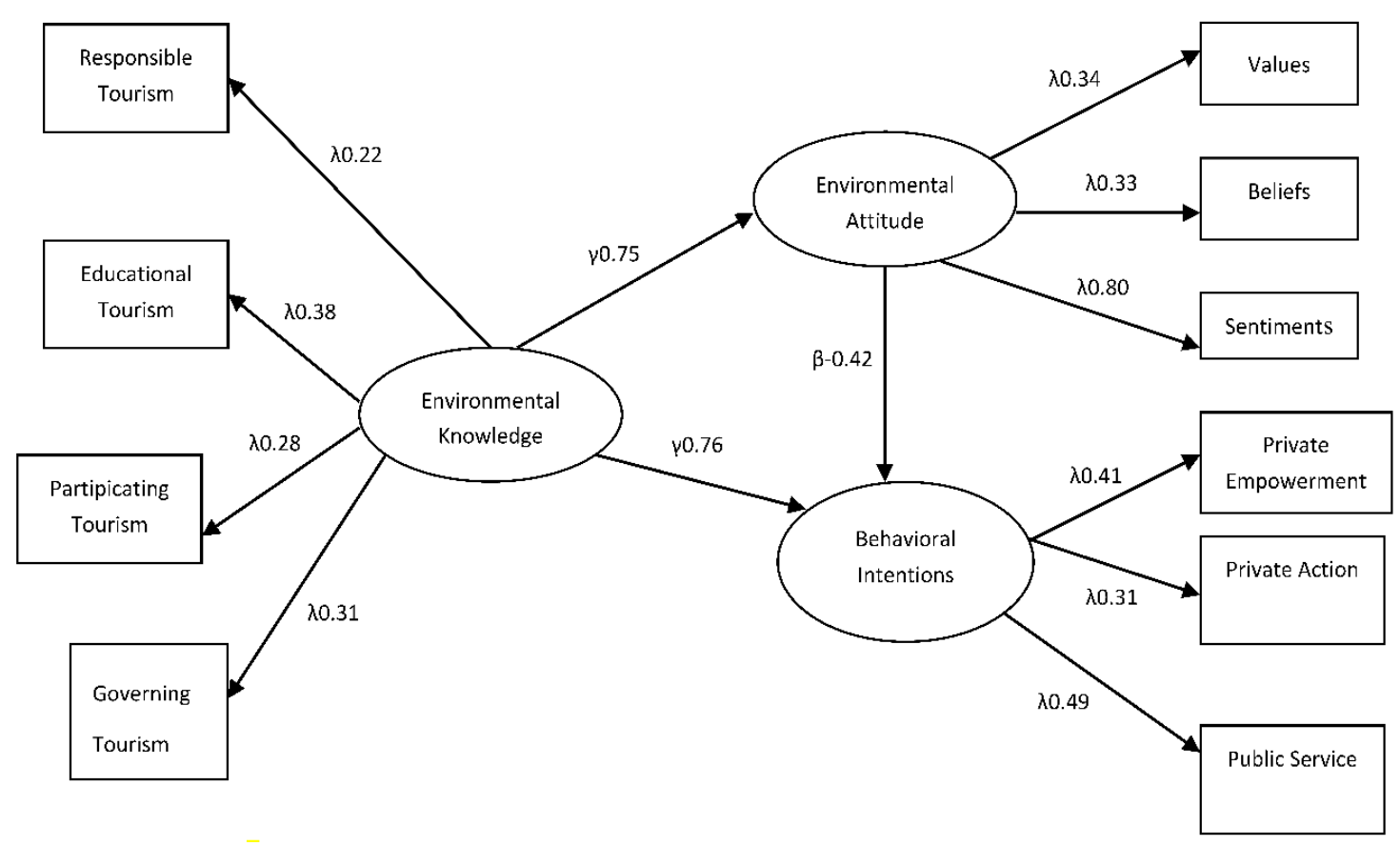

Figure 7. Empirical structure of environmental concern in Chinese students $(n=420)$.

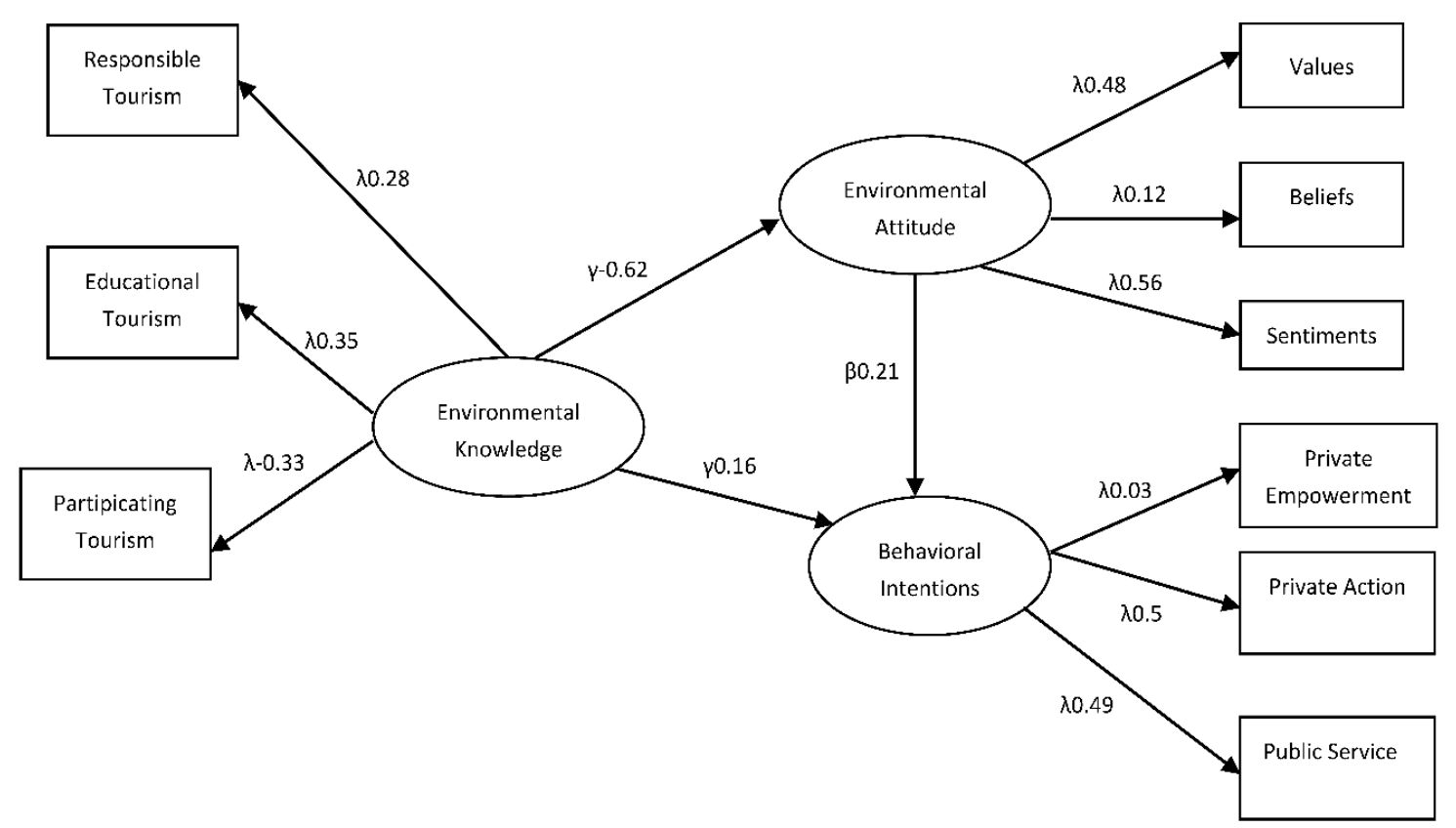

Figure 8. Empirical structure of environmental concern in Taiwanese students $(n=415)$. 


\subsection{Findings}

The results shown in Figure 7 reflect the relative levels of conceptual emphasis on the causal relationships among these three dimensions in the ecotourism environmental literacy of Chinese university students. In the case of Chinese university students, the correlation coefficients $(\beta, \gamma)$ calculated between the three factor dimensions of environmental knowledge, environmental attitude, and behavioral intentions in ecotourism environmental literacy were as follow: 0.76, calculated for 'environmental knowledge affects behavioral intentions' (Hypothesis 2: supported; $\gamma=0.76$, $t$-value $=2.31) ; 0.75$, calculated for 'environmental knowledge affects environmental attitude' (Hypothesis 1: supported; $\gamma=0.75, t$-value $=5.50$ ); and -0.42 , calculated for 'environmental attitude affects behavioral intentions' (Hypothesis 3: not supported; $\beta=-0.42$, $t$-value $=-1.10$ ). The values of the correlation coefficients obtained in this analysis indicated that among the three factor dimensions of ecotourism environmental literacy, the explanatory power was highest in the case of the factor dimension 'environmental knowledge affects behavioral intentions', and it was followed by 'environmental knowledge affects environmental attitude'.

In the case of Taiwanese university students (see Figure 8 ), the correlation coefficients $(\beta, \gamma)$ calculated between the three factor dimensions of environmental attitude, environmental knowledge, and behavioral intentions were as follows: 0.21, calculated for 'environmental attitude affects behavioral intentions' (Hypothesis 3: supported; $\beta=0.21, t$-value $=1.36$ ); 0.16 , calculated for 'environmental knowledge affects behavioral intentions' (Hypothesis 2: supported; $\gamma=0.16$, $t$-value $=1.26$ ); and -0.62 , calculated for 'environment knowledge affects environmental attitude' (Hypothesis 1: not supported; $\gamma=-0.62, t$-value $=6.85$ ). The size of the $\lambda$ coefficient in the analysis indicated that among the three factor dimensions of ecotourism environmental literacy, explanatory powers were exhibited by 'environmental knowledge affects behavioral intentions' and 'environmental knowledge affects environmental attitude', but the correlation was extremely weak. Therefore, the results confirmed the findings of Ajzen and Fishbein, and Best and Mayerl [52,64]. Weak bivariate correlations existed between environmental attitude (i.e., attitudes and values) and environmental behavior because of the absence of direct effects in both Chinese and Taiwanese students. The results also showed that the environmental knowledge of ecotourism affect behavioral intentions in both Chinese and Taiwanese university students. In terms of correlation, the environmental ecotourism behavioral intentions of Chinese students were stronger than those of Taiwanese students and exhibited a positive relationship $(\gamma=0.76)$. Based on the $\lambda$ coefficient, the behavioral intentions of Chinese university students were ranked in the following sequence: public service $(\lambda=0.49)$, private empowerment $(\lambda=0.41)$, and private action $(\lambda=0.31)$. In the aforementioned knowledge of Chinese university students, ecotourism was ranked in the following sequence: educational tourism $(\lambda=0.38)$, governing tourism $(\lambda=0.31)$, participating tourism $(\lambda=0.28)$, and responsible tourism $(\lambda=0.22)$.

Among the Taiwanese university students, those who exhibited high environmental knowledge in ecotourism also exhibited behavioral intentions in ecotourism, but the correlation was weak $(\gamma=0.16)$. The behavioral intentions of Taiwanese university students were ranked in the following sequence: private action $(\lambda=0.52)$, public service $(\lambda=0.49)$, and private empowerment $(\lambda=0.03)$. The Taiwanese university students' knowledge of the definition of ecotourism included educational tourism $(\lambda=0.35)$ and responsible tourism $(\lambda=0.28)$, but not participating tourism $(\lambda=-0.33)$. Furthermore, in the confirmatory factor analysis, the measurement results of governing tourism deviated considerably from the Taiwanese university students' knowledge of ecotourism and did not constitute the sub-dimensions, and thus these measurement results were omitted.

\section{Discussion}

In East Asia, both China and Taiwan are increasingly promoting ecotourism, but ecotourism has been developed to distinct levels because of the use of dissimilar political systems in these places. Both regions had been subjected to some controversial debates for true ecotourism. In Taiwan, for example, six Indigenous Seidok tribes had jointly developed ecotourism in Nantou County. 
This ecotourism program was supported by the government, with the intention to combine factual history associated with Seidok culture and local tourism. The successful stories were detected in Taiwan because this island nation features a prosperous economy, universal education, and a solid middle class, and Taiwan has successfully transformed from an authoritarian political system to a Western-style democracy.

In China, ecotourism was also an emerging sector which had gained substantial attention [65]. For example, new ecotourism resorts (e.g., Naked Stables Private Reserve, Red Capital Ranch) were built to promote ecotourism and sustainability as China sought to improve its global environmentalism reputation. Although the market is gradually opening up, and with people's lives improving, the voice for freedom and democracy is getting increasingly loud; however, China still adheres to a mixed socialism and state-capitalism system [66].

\subsection{Ecotourism Knowledge Affects Behavioral Intentions}

Results revealed that ecotourism knowledge affects the behavioral intentions of both Chinese and Taiwanese university students, and that this correlation was stronger in the case of Chinese university students than to their Taiwanese counterparts. There is inadequate environmental education intervention provided at the university level in China and Taiwan, and thus it is challenging to construct an environmental teaching module featuring a theoretical background that has been demonstrated to be effective. Therefore, in the planning of environmental education curriculum in China and Taiwan, the 'knowledge-attitude-behavior' theory is still accepted: the education system accepts the notion that increasing environmental knowledge can change a person's attitude toward the environment and produce responsible environmental behavior [67]. Thus, considerable argument and controversy exists regarding whether or not environmental attitude is the intermediary variable of environmental knowledge and environmental behavior. Because the concept of the 'knowledge-attitude-behavior' theory is used, the environmental education curriculum in China and Taiwan leans toward a one-way transfer of knowledge. However, a transfer of knowledge is not equal to the construction of environmental values and judgment. Grob [51] reported that no effects on environmental behavior stemming from factual knowledge could be identified, thus the relationship between knowledge and behavior could not be established. Moreover, several studies have shown that a high degree of correlation does not necessarily exist among knowledge, sentiment, and behavior, and Fishbein reported that sentiment, knowledge, and behavior are not always strongly correlated [68]. However, the findings in this study suggested that an accurate understanding of ecotourism by Chinese and Taiwanese university students will elicit environmentally friendly behavioral intentions, which in turn lead to having comprehensive knowledge of ecotourism that will produce a self-driven ability to engage in environmentally friendly behaviors.

\subsection{Disparities in Chinese and Taiwanese University Students' Ecotourism Behavioral Intentions}

With regards to self-empowerment for personal improvement, the Taiwanese university students responded that they did not commonly read explanatory signs and billboards posted by the government in ecotourism areas, and the students displayed a high level of personal awareness of ecotourism and many expressed distrusts in the government. In terms of self-learning behaviors in ecotourism, Taiwanese university students stressed autonomy, and from the perspective of receiving multiple messages from communication media, the students pursued diverse values, expressed autonomous awareness, and opposed the self-centered concept of a centralized consciousness than the Chinese university students did.

The curriculum structures used in university education in both China and Taiwan emphasize the civil rights and obligations stipulated by the Constitution and the protection of the law. The university education in Taiwan introduced 'beneficial interest', university students have exhibited increased self-interest and have received increased personal rights protections. In contrast, China's university 
education introduced 'supervisory powers', and the university students have enjoyed limited freedom of speech and increased powers of self-advocacy compared to Post-Mao era (1976-1989).

In promoting the concept of ecotourism, Chinese and Taiwanese university students might differ in terms of what influences the formation of the environmental protection concept or in terms of the factors of educational environment and intention of participation. Nevertheless, the results indicated that the cross-strait university students who participated in this study displayed certain similarities in environmental literacy related to ecotourism. Although students in both China and Taiwan fully affirm the prospects of ecotourism, but Chinese university students expressed a greater desire for ecotourism than did the Taiwanese university students, who have been living in a free society.

\section{Conclusions, Recommendations, Limitations and Future Research}

\subsection{Conclusions}

In conclusion, this study has compared university students in China and Taiwan in terms of their ecotourism environmental literacy. The results showed that the knowledge of ecotourism affects behavioral intentions. Specifically, the Chinese university students demonstrated a higher correlation between knowledge of ecotourism and behavioral intentions than the Taiwanese students. Furthermore, Chinese university students considered ecotourism to be a business that should be under governmental control. In terms of behavior, the desire for gaining knowledge for the purpose of self-empowerment was weaker in the Taiwanese university students than in the Chinese students.

\subsection{Recommendations}

Based on the aforementioned findings, it is recommended that the level of importance attached to 'environmental knowledge' in Taiwan ecotourism education be slightly reduced because knowledge alone cannot always generate positive value judgment. Therefore, environmental education in Taiwan should focus instead on nurturing the training provided for environmental attitude and environment-friendly behaviors, to develop environmentally conscious citizens raised with high-quality environmental literacy. In addition, the participation rates of ecotourism are low, and learning opportunities of ecotourism concepts through relevant courses at the university are limited. We recommend that both regions increase the number of courses that offer greater insights about environmental education on ecotourism. A closer exchange between Chinese and Taiwanese students will allow the mutual communication to alter the knowledge of university students in both places and generate a fusion of ideas and action. As Taiwan gradually receives increased numbers of tourists/sightseers from China, the frequency of exchanges between the two sides will also increase [69]. Cross-strait exchanges in ecotourism will be promoted, and the political gap between the two sides will be eliminated. This study is intended to provide a new discourse and new ideas for higher education and research on ecological tourism in China and Taiwan and thus improves tourism education and environmental education in both places.

\subsection{Limitations and Future Research}

This study is only a preliminary exploration of university students' ecotourism and environmental literacy with selected universities in China and Taiwan, and therefore cannot be generalized to other contexts. Another limitation in this study is the absence of interviews with academics who can assist in determining if the course syllabi cover the relevant tourism contents, which may help enhance the research methodology and instrument design. Although the purpose for the provision of a clear definition of the term "ecotourism" to the participants prior to the survey is to ensure a consistent understanding of what "ecotourism" refers to in the questionnaire, but this may potentially affect the results of some questions related to ecotourism.

The relation between behavioral intentions and the observed behavior of people is needed for further studies, to determine if intentions are reflected as actual actions. Further studies from personal 
observation associated self-reports studies are required to solve this research gap toward sustainable tourism. In addition, future research can explore possible correlation between political systems and university student knowledge and attitudes toward ecotourism, and also the student's area of study to determine if their attitudes towards ecotourism may be affected.

Author Contributions: W.-T.F. conceived and designed the experiments; W.-T.F., C.-Y.L., and G.H performed the experiments; W.-T.F. analyzed the data; S.-W.L., W.-T.F., Y.-W.H, G.H., G.-S.S, J.-Y.C., E.N. contributed reagents/materials/analysis tools; W.-T.F., C.-Y.L., and E.N. wrote the paper.

Acknowledgments: We thank members of the Graduate Institute of Environmental Education, National Taiwan Normal University (NTNU, Taipei, Taiwan) and the Department of Tourism and Leisure, Chung Hua University for their contributions to the manuscript. This work was supported by grants from the Ministry of Science and Technology under Grant numbers MOST 103-2511-S-237 -003 to Wei-Ta Fang \& Ching-Yu Lien; MOST-105-2511-S-003-021-MY3 to Wei-Ta Fang. This article was also subsidized by the National Taiwan Normal University (NTNU) and Taiwan Nature Trail Society, Taiwan, ROC. The useful suggestions from anonymous reviewers were incorporated into the manuscript.

Conflicts of Interest: The authors declare no conflicts of interest.

\section{Appendix A}

Questions about environmental knowledge, environmental attitude, and behavioral intentions Reverse scoring using (R) $\left(x,{ }^{\prime} 1=5 ; 2=4 ; 3=3 ; 4=2 ; 5=1^{\prime}\right)$

\section{A.1. Environmental Knowledge (16 Items)}

\section{A.1.1. Responsible Tourism}

Ecotourism should consider wildlife habitats

Ecotourism should pay attention to stakeholders' rights

Ecotourism should conserve natural and human resources toward sustainability

Ecotourism should pay attention to protect local historical images

\section{A.1.2. Educational Tourism}

Ecotourism should persuade tourists to actively participate in environmental protection through environmental education

Ecotourism should cooperate with full and complete interpretation content

Ecotourism should be a small-team learning tour and not a bunch of people's consuming tour

\section{A.1.3. Participating Tourism}

Environmental groups should assist in ecological interpretation and environmental protection in ecotourism areas

Residents of ecotourism areas should have the right to participate in tourism development, decision making, and interpretation design

The operating income of the ecotourism areas should be returned to the local community

\section{A.1.4. Governing Tourism}

Government units should formulate regulations on ecological protection in ecotourism areas

Environmentalists should strictly play the role of supervisor and provide advice in ecotourism areas

Government units should ensure that resources are used correctly in ecotourism areas 
Ecotourism operators should receive professional certification

Ecotourism should utilize legislation to regulate the use of natural resources

Ecotourism should delineate more animal protection areas

\section{A.2. Environmental Attitude (14 Items)}

\section{A.2.1. Values}

Natural resources are inexhaustible. (R)

It is feasible to convert all agroforestry to other uses. (R)

Humans can control other organisms in order to survive. (R)

Interpretation is very important for ecotourism

Compared with environmental protection, economic development should be emphasized. (R)

Ecotourism should be paid more than other travel types

\section{A.2.2. Beliefs}

Ecotourism should emphasize the fairness of animals and plants

Ecotourism should emphasize the importance and rarity of the environment

Visitors should learn to respect nature and humanistic environment in ecotourism

Ecotourism should respect and understood local customs and lifestyles

\section{A.2.3. Sentiments}

China's environmental protection work has done very well so far/Taiwan's environmental protection work has been done very well so far. (R)

What I thought that the process of ecotourism can have a serious impact on wildlife and their habitats. (R)

It is an immoral act to destroy or contaminate natural resources in protected areas

Once the natural environment is destroyed or contaminated, it is difficult to recover

\section{A.3. Behavioral Intentions (8 Items)}

\section{A.3.1. Private Empowerment}

During travelling, I will carefully read the guidance to the wildlife and plants in details

During travelling, I will join in listening to natural interpretation from tour guides

During travelling, I will communicate with local residents to understand the local culture

\section{A.3.2. Private Action}

During travelling, I will endure less convenient public facilities

During travelling, I would refuse to buy if the stores' salesmen are not eco-friendly (i.e., if they provide disposable tableware in restaurants)

During travelling, I will bring my own tableware and water bottles 


\section{A.3.3. Public Service}

Seeing other tourists littering, I will persuade him

I will take the initiative to report to the relevant authorities when I detect the environment to be damaged

\section{References}

1. Wu, K.-S.; Teng, Y.-M. Applying the extended theory of planned behavior to predict the intention of visiting a green hotel. Afr. J. Bus. Manag. 2011, 5, 7579-7587.

2. Gössling, S.; Peeters, P. Assessing tourism's global environmental impact 1900-2050. J. Sustain. Tour. 2015, 23, 639-659. [CrossRef]

3. Wearing, S.; Neil, J. Ecotourism: Impacts, Potentials and Possibilities, 2nd ed.; Butterworth-Heinemann: Oxford, UK, 2009.

4. Butcher, J. The United Nations International Year of Ecotourism: A critical analysis of development implications. Prog. Dev. Stud. 2006, 6, 146-156. [CrossRef]

5. Weaver, D.B.; Lawton, L.J. Twenty years on: The state of contemporary ecotourism research. Tour. Manag. 2007, 28, 1168-1179. [CrossRef]

6. Blangy, S.; Mehta, H. Ecotourism and ecological restoration. J. Nat. Conserv. 2006, 14, 233-236. [CrossRef]

7. Stem, C.J.; Lassoie, J.P.; Lee, D.R.; Deshler, D.D.; Schelhas, J.W. Community participation in ecotourism benefits: The link to conservation practices and perspectives. Soc. Nat. Resour. Int. J. 2003, 16, 387-413. [CrossRef]

8. Russell, C.L. Ecotourism as experiential environmental education? J. Exp. Educ. 1994, 17, 16-22. [CrossRef]

9. Powell, R.B.; Ham, S.H. Can ecotourism interpretation really lead to pro-conservation knowledge, attitudes and behaviour? Evidence from the Galapagos Islands. J. Sustain. Tour. 2008, 16, 467-489. [CrossRef]

10. Hetzer, N.D. Environment, tourism, culture. LINKS 1965. Reprinted in Ecosphere 1970, 1, 1-3.

11. Honey, M. Ecotourism and Sustainable Development, Who Owns Paradise? Island Press: Washington, DC, USA, 2008.

12. Saarinen, J. Traditions of sustainability in tourism studies. Ann. Tour. Res. 2006, 33, 1121-1140. [CrossRef]

13. Bianchi, R. Tourism restructuring and the politics of sustainability: A critical view from the European Periphery (The Canary Islands). J. Sustain. Tour. 2004, 12, 495-529. [CrossRef]

14. Ceballos-Lascurain, H. The future of ecotourism. Mex. J. 1987, 1, 13-19.

15. Dolnicar, S.; Crouch, G.I.; Long, P. Environment-friendly tourists: What do we really know about them? J. Sustain. Tour. 2008, 16, 197-210. [CrossRef]

16. $\mathrm{Xu}, \mathrm{F}$; Fox, D. Modelling attitudes to nature, tourism and sustainable development in national parks: A survey of visitors in China and the UK. Tour. Manag. 2014, 45, 142-158. [CrossRef]

17. Scheyvens, R. Ecotourism and the empowerment of local communities. Tour. Manag. 1999, 20, 245-249. [CrossRef]

18. Hungerford, H.R.; Volk, T.L. Changing learner behavior through environmental education. J. Environ. Educ. 1990, 21, 8-21. [CrossRef]

19. Roth, C.E. Environmental Literacy: Its Roots, Evolution and Directions in the 1990s; ERIC/CSMEE: Columbus, OH, USA, 1992.

20. Teksoz, G.; Sahin, E.; Tekkaya-Oztekin, C. Modeling environmental literacy of university students. J. Sci. Educ. Technol. 2012, 21, 157-166. [CrossRef]

21. Goldman, D.; Pe'er, S.; Yavetz, B. Environmental literacy of youth movement members-Is environmentalism a component of their social activism? Environ. Educ. Res. 2017, 23, 486-514. [CrossRef]

22. McBride, B.B.; Brewer, C.A.; Berkowitz, A.R.; Borrie, W.T. Environmental literacy, ecological literacy, ecoliteracy: What do we mean and how did we get here? Ecosphere 2013, 4, 1-20. [CrossRef]

23. Gupta, G.; Chopra, P. Eco-tourists and environment protection: A pro-environment behavioural segmentation approach. Amity Glob. Bus. Rev. 2014, 9, 90-95.

24. Wurzinger, S.; Johansson, M. Environmental concern and knowledge of ecotourism among three groups of Swedish tourists. J. Travel Res. 2006, 45, 217-226. [CrossRef] 
25. Tsaur, S.H.; Lin, Y.C.; Lin, J.H. Evaluating ecotourism sustainability from the integrated perspective of resource, community and tourism. Tour. Manag. 2006, 27, 640-653. [CrossRef]

26. Juvan, E.; Dolnicar, S. The attitude-behaviour gap in sustainable tourism. Ann. Tour. Res. 2014, 48, 76-95. [CrossRef]

27. Bergin-Seers, S.; Mair, J. Emerging green tourists in Australia: Their behaviours and attitudes. Tour. Hosp. Res. 2009, 9, 109-119. [CrossRef]

28. Jackson, T. Motivating sustainable consumption. Sustain. Dev. Res. Netw. 2005, 29, 30.

29. Tosun, C. Limits to community participation in the tourism development process in developing countries. Tour. Manag. 2000, 21, 613-633. [CrossRef]

30. Lai, P.H.; Nepal, S.K. Local perspectives of ecotourism development in Tawushan Nature Reserve, Taiwan. Tour. Manag. 2005, 27, 1117-1129. [CrossRef]

31. Medina, L.K. Ecotourism and certification: Confronting the principles and pragmatics of socially responsible tourism. J. Sustain. Tour. 2005, 13, 281-295. [CrossRef]

32. Ohe, Y. Evaluating operators' attitudes to educational tourism in dairy farms: The case of Japan. Tour. Econ. 2012, 18, 577-595. [CrossRef]

33. Samah, A.A.; Ahmadian, M. Educational tourism in Malaysia: Implications for community development practice. Asian Soc. Sci. 2013, 9, 17. [CrossRef]

34. Maikhuri, R.K.; Rana, U.; Rao, K.S.; Nautiyal, S.; Saxena, K.G. Promoting ecotourism in the buffer zone areas of Nanda Devi Biosphere Reserve: An option to resolve people-Policy conflict. Int. J. Sustain. Dev. World Ecol. 2000, 7, 333-342. [CrossRef]

35. Sofield, T.; Li, S. Tourism governance and sustainable national development in China: A macro-level synthesis. J. Sustain. Tour. 2011, 19, 501-534. [CrossRef]

36. Bamberg, S. How does environmental concern influence specific environmentally related behaviours? A new answer to an old question. J. Environ. Psychol. 2003, 23, 21-32. [CrossRef]

37. Grob, A. A structural model of environmental attitudes and behaviour. J. Environ. Psychol. 1995, 15, $209-220$. [CrossRef]

38. McKechnie, G.E. Measuring environmental dispositions with the environmental response inventory. In Proceedings of the 2nd Annual Environmental Design Research Association Conference, Pittsburgh, PA, USA, October 1970; pp. 320-326.

39. Hines, J.M.; Hungerford, H.R.; Tomera, A.N. Analysis and synthesis of research on responsible environmental behaviour: A meta-analysis. J. Environ. Educ. 1987, 18, 1-8. [CrossRef]

40. Ajzen, I. The theory of planned behaviour. Organ. Behav. Hum. Decis. Process. 1991, 50, 179-211. [CrossRef]

41. Chen, M.F.; Tung, P.J. Developing an extended theory of planned behavior model to predict consumers' intention to visit green hotels. Int. J. Hosp. Manag. 2014, 36, 221-230. [CrossRef]

42. Cheng, T.M.; Wu, H.C. How do environmental knowledge, environmental sensitivity, and place attachment affect environmentally responsible behavior? An integrated approach for sustainable island tourism. J. Sustain. Tour. 2015, 23, 557-576. [CrossRef]

43. Hungerford, H.R.; Peyton, R.B. A Paradigm of Environmental Action. ERIC Documentation Service ED137116. 1977. Available online: https:/ / eric.ed.gov/?id=ED137116 (accessed on April 10 2018).

44. Lee, $\mathrm{K}$. The role of media exposure, social exposure and biospheric value orientation in the environmental attitude-intention-behavior model in adolescents. J. Environ. Psychol. 2011, 31, 301-308. [CrossRef]

45. Zsóka, Á.; Szerényi, Z.M.; Széchy, A.; Kocsis, T. Greening due to environmental education? Environmental knowledge, attitudes, consumer behavior and everyday pro-environmental activities of Hungarian high school and university students. J. Clean. Prod. 2013, 48, 126-138. [CrossRef]

46. Kaiser, F.G.; Wölfing, S.; Fuhrer, U. Environmental attitude and ecological behaviour. J. Environ. Psychol. 1999, 19, 1-19. [CrossRef]

47. Pooley, J.A.; O'Connor, M. Environmental education and attitudes emotions and beliefs are what is needed. Environ. Behav. 2000, 32, 711-723. [CrossRef]

48. Kruglanski, A.W. Lay Epistemics and Human Knowledge: Cognitive and Motivational Bases; Plenum: Newark, UK, 1989.

49. De Rosis, F.; Castelfranchi, C.; Goldie, P.; Carofiglio, V. Cognitive Evaluations and Intuitive Appraisals: Can Emotion Models Handle Them Both? In Emotion-Oriented Systems; Springer: Berlin/Heidelberg, Germany, 2011; pp. 459-481. 
50. Best, H.; Mayerl, J. Values, beliefs, attitudes: An empirical study on the structure of environmental concern and recycling participation. Soc. Sci. Q. 2013, 94, 691-714. [CrossRef]

51. Freed, A. The relationship between university students' environmental identity, decision-making process, and behavior. Environ. Educ. Res. 2018, 24, 474-475. [CrossRef]

52. Neisser, U. Cognitive Psychology; Prentice-Hall: Englewood Cliffs, NJ, USA, 1967.

53. Revlin, R. Cognition: Theory and Practice; Worth Publishers: New York, NY, USA, 2013.

54. Hollweg, K.S.; Taylor, J.R.; Bybee, R.W.; Marcinkowski, T.J.; McBeth, W.C.; Zoido, P. Developing a Framework for Assessing Environmental Literacy; North American Association for Environmental Education: Washington, DC, USA, 2011; Available online: http:/ / www.naaee.net (accessed on 10 April 2018).

55. Tuncer, G.; Tekkaya, C.; Sungur, S.; Cakiroglu, J.; Ertepinar, H.; Kaplowitz, M. Assessing pre-service teachers' environmental literacy in Turkey as a mean to develop teacher education programs. Int. J. Educ. Dev. 2009, 29, 426-436. [CrossRef]

56. Erdogan, M.; Ok, A. An assessment of Turkish young pupils' environmental literacy: A nationwide survey. Int. J. Sci. Educ. 2011, 33, 2375-2406. [CrossRef]

57. McBeth, W.; Volk, T.L. The national environmental literacy project: A baseline study of middle grade students in the United States. J. Environ. Educ. 2009, 41, 55-67. [CrossRef]

58. McKeown-Ice, R. Environmental education in the United States: A survey of preservice teacher education programs. J. Environ. Educ. 2000, 32, 4-11. [CrossRef]

59. Walter, P.G. Theorising visitor learning in ecotourism. J. Ecotour. 2013, 12, 15-32. [CrossRef]

60. Kline, R.B. Principles and Practice of Structural Equation Modelling, 4th ed.; Guilford: New York, NY, USA, 2016.

61. Bentler, P.M. EQS 6 Structural Equations Program Manual; Multivariate Software: Encino, CA, USA, 2006.

62. Hu, L.; Bentler, P.M. Cutoff criteria for fit indexes in covariance structure analysis: Conventional criteria versus new alternatives. Struct. Equ. Model. 1999, 6, 1-55. [CrossRef]

63. McDonald, R.P.; Ho, M.H.R. Principles and practice in reporting statistical equation analyses. Psychol. Methods 2002, 7, 64-82. [CrossRef] [PubMed]

64. Ding, L.; Velicer, W.F.; Harlow, L.L. Effects of estimation methods, number of indicators per factor, and improper solutions on structural equation modeling fit indices. Struct. Equ. Model. Multidiscip. J. 1995, 2, 119-143. [CrossRef]

65. Qian, J.; Shen, H.; Law, R. Research in sustainable Tourism: A longitudinal study of articles between 2008 and 2017. Sustainability 2018, 10, 590. [CrossRef]

66. Bremmer, I. State capitalism comes of age: The end of the free market? Foreign Aff. 2009, 88, 40-55.

67. Shi, L.; Wang, G. A survey on environmental awareness and behaviours of college-student tourists in China. Environ. Sci. Technol. 2012, 35, 193-196.

68. Fishbein, M. Attitude and the prediction of behaviour. In Readings in Attitude Theory and Measurement; Fishbein, M., Ed.; John Wiley \& Sons: New York, NY, USA, 1967; pp. 477-492.

69. Mainland China, Visitors Arrivals 2012-2017. Available online: http://stat.taiwan.net.tw/system/country_ years_arrival_result.asp?101\&106\&1\&2\&\%E4\%B8\%AD \%E5\%9C\%8B\%E5\%A4\%A7\%E9\%99\%B8\%3Cbr\% 3E(Mainland\%20China) (accessed on 31 May 2018).

(C) 2018 by the authors. Licensee MDPI, Basel, Switzerland. This article is an open access article distributed under the terms and conditions of the Creative Commons Attribution (CC BY) license (http://creativecommons.org/licenses/by/4.0/). 